\title{
Trees of knowledge
}

\author{
Georg Lichtenberg visualized a new branch of science.
}

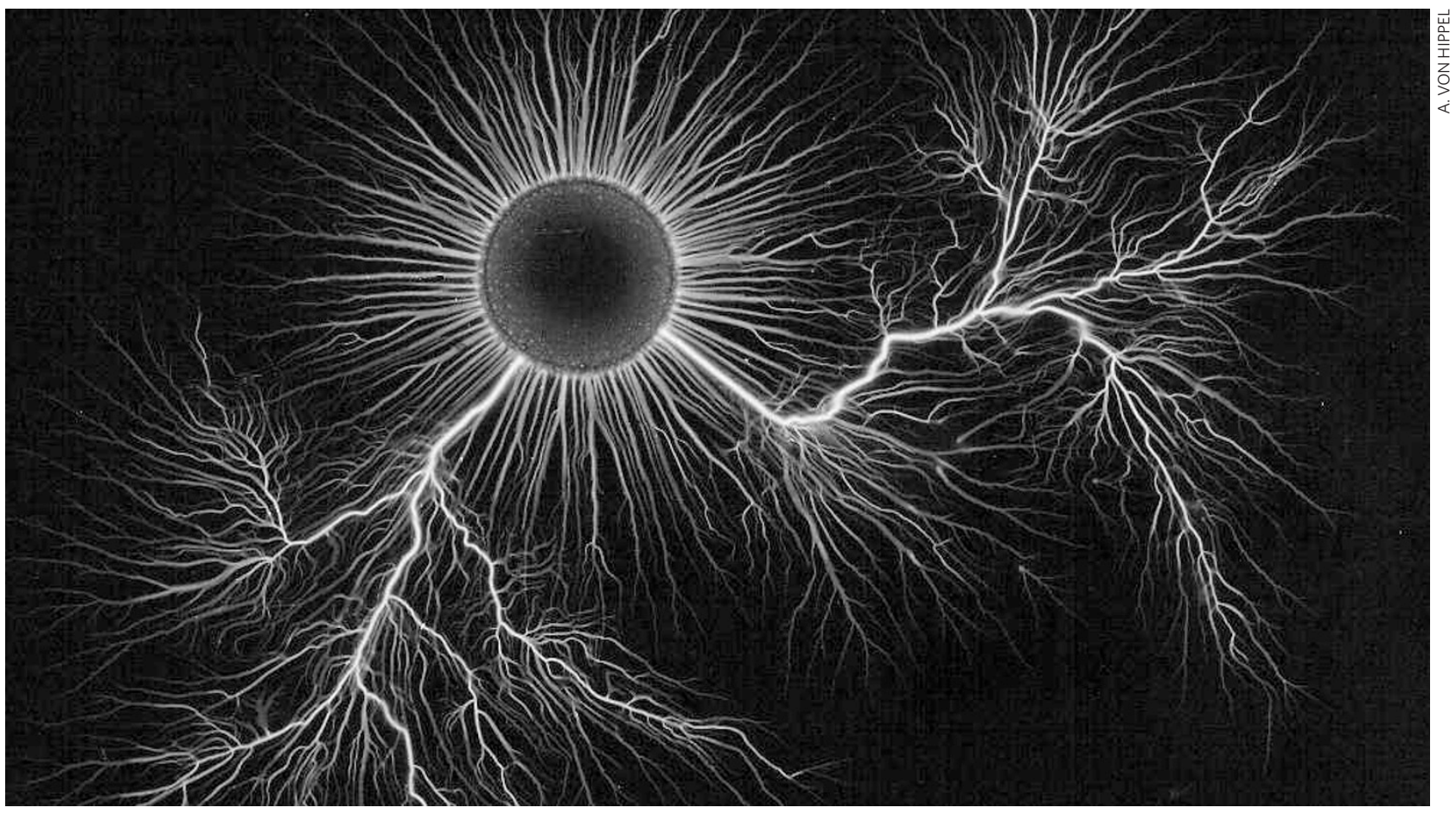

Martin Kemp

There is something compelling about a phenomenon that can inscribe itself, drawing its own diagram through the direct visual recording of traces of its activity. We are familiar with these kinds of traces in the cloud and bubble chambers of atomic science, but the idea that the unseen forces of nature might reveal their actions through visible traces has a much longer history.

Acoustics was probably the first field to visualize such forces. As early as 1680, Robert Hooke studied wave formations in flour on glass plates agitated by a violin bow. This began a tradition of materializing sound that passed via Ernst Chladni in 1787 and Hermann von Helmholtz to modern oscilloscopes.

But nowhere were the results of direct transcription more spectacular than in the new science of electricity in the late eighteenth century. Working at the University of Göttingen, Germany, as professor of physics, Georg Christoph Lichtenberg stumbled across the explosively beautiful dendritic structures of electrical discharge that still bear his name. The activities of this humorist, polemicist and moralist ranged from the mathematical sciences and physiognomics to commentaries on William Hogarth's satirical engravings. It was while he was experimenting with static electricity on a huge cake of resin that he discovered Lichtenberg figures, partly by chance. He was fascinated to observe that dust had accumulated into a radiating formation of startling refinement and complexity. The direct inscription of Lichtenberg figures on to a photographic plate was accomplished by Arthur von Hippel and his student Fred Merrill in the late 1930s. They set up an impulse generator and pressure tank so that they could record photographically the effect of an electrical discharge in any gas over a wide range of pressures. The resulting images (see above), as von Hippel realized, have extraordinary visual properties. Neatly capturing the nature of lightning, the photographs "transfer terror into enchantment", as Lichtenberg put it, and manifest art in science.

Four of the Lichtenberg figures obtained by von Hippel and Merrill feature in a fascinating exhibition exploring the ramifications of dendritic structures, Einfach Komplex (Simply Complex). The exhibition, curated by Barbara Bader, Andres Janser and Marius Kwint, can be seen at the Museum of Design in Zurich, Switzerland, until 4 September. Featuring images of trees in science, it not only presents us with a visual feast of naturally occurring structures that provide variations on fractal branching systems, and with works of artists and designers who are fascinated by dendritic formations, but also encourages us to journey into the conceptual branches of the organization of knowledge.

As the curators show, tree-shaped 'organograms' have provided schematic forms for the organization of intellectual fields, encyclopedias, digitized data, languages, artistic styles, biological evolution, voter choice and much more. Few of us who work in large organizations can have escaped being located somewhere on a ramifying chart of line management and accountability.

What the physically generated forms (such as the Lichtenberg figures) and the conceptual models generally have in common is a basic rule of branching structures: thick branches tend to give rise to progressively thinner ones in a proportional manner. Lichtenberg himself sensed some kind of affinity between the 'folds' of his thought and the tendrils of his figures.

But Lichtenberg would probably have resisted the schematization of thinking that can too easily accompany the condensing of complex phenomena into diagrams of branching structures, just as he rejected the easy formulas of physiognomics for judging someone's character. He was well aware of the sheer complexity of nature, human character and society. As one of the greatest ever writers of aphorisms, it is fitting that he should have the last word: "The noble simplicity in the works of nature only too often originates in the noble shortsightedness of he who observes it." Martin Kemp is professor of the history of art at the University of Oxford, Oxford OX11PT, UK, and is the author of Leonardo (Oxford University Press, 2004). 